\title{
Pattern of blood donor deferral in a tertiary hospital, South-south, Nigeria: A three-year study review
}

\section{Timothy Amos Ekwere, Mabel Ino-Ekanem, Olugbemi Oluseyi Motilewa, Iquo Augustine Ibanga}

\begin{abstract}
Aims: Provision of safe and adequate supply of blood and blood products is a major public health issue globally. Safe blood is ensured through proper donor selection and testing of donated blood. However, a large number of apparently healthy donors are unable to donate blood for various reasons. To determine the proportions and reasons for donor deferral in University of Uyo Teaching Hospital (UUTH) Blood Bank. Methods: A three-year retrospective review of records of blood donors from January 2009 to December 2012 was analyzed to determine the proportions and reasons for donor deferral in University of Uyo Teaching Hospital blood bank. Results: There were 5,636 donors of which 902 donors representing $16 \%$ of the entire donor population were deferred for various reasons. Large proportions $(89.1 \%)$ of the donors were family replacement donors. Female donors constitute $16 \%$ of the entire donor population and were more frequently deferred than male donors $34.4 \%$ versus $12.4 \%$, respectively. Transfusion transmissible infections (TTIs) positivity and
\end{abstract}

Timothy Amos Ekwere ${ }^{1}$, Mabel Ino-Ekanem¹, Olugbemi Oluseyi Motilewa ${ }^{2}$, Iquo Augustine Ibanga ${ }^{3}$

Affiliations: ${ }^{1}$ Lecturer, Department of Hematology, College of Health Sciences, University of Uyo, Uyo, Akwalbom, State, Nigeria; 'Lecturer, Department of Community Health, College of Health Sciences, University of Uyo, Uyo, Akwalbom State, Nigeria; ${ }^{3}$ Senior Lecturer, Department of Hematology, College of Medical Sciences, University of Calabar, Calabar, Cross-River State, Nigeria.

Corresponding Author: Timothy Amos Ekwere, Department of Hematology, College of Health Sciences, University of Uyo, Uyo, Akwalbom State, Nigeria; Ph: +234-803-5791835; Email: timothyekwere@yahoo.com

Received: 20 May 2014

Accepted: 06 June 2014

Published: 31 July 2014 anemia were the major reasons for permanent (50.4\%) and temporary (39\%) deferral of donors. The TTIs rates were higher among male donors than female donors. Conversely, more female donors were anemic (25.6\%) compared to male (12.7\%). Other reasons identified for donor deferral were underage $(6.8 \%)$, underweight (2.4\%), and hypertension (3.1\%). Conclusion: A donor deferral rate of $16 \%$ in this study is similar to that reported in other studies. However, the reasons for deferral differ reflecting differences in donor selection criteria.

Keywords: Blood donation, Donor deferral, Blood safety, Transfusion transmissible infections (TTIs)

\section{How to cite this article}

Ekwere TA, Ino-Ekanem M, Motilewa OO, Iquo Augustine Ibanga. Pattern of blood donor deferral in a tertiary hospital, South-south, Nigeria: A three-year study review. Int $\mathrm{J}$ Blood Transfus Immunohematol 2014;4:7-13.

Article ID: 100014IJBTITE2014

$* * * * * * * * *$

doi:10.5348/ijbti-2014-14-OA-2

\section{INTRODUCTION}

The main goal of blood transfusion services (BTS) globally is ensuring the availability of safe and adequate supply of blood and blood products. To achieve this, blood for transfusion must be obtained from voluntary nonremunerated blood donors (VNRD) [1]. Blood transfusion services are thus saddle with the responsibility of collecting 
blood only from VNRD who are at low risk for transfusion transmissible infections (TTIs) and who are unlikely to jeopardize their own health through falsification of their health status in other to donate blood [1].

A stringent process of donor selection aimed at assessing the suitability of prospective donors is therefore essential in ensuring the safety and sufficiency of blood supply, safeguard the health of the recipients of transfusion as well as that of the donors, and at the same time ensures that suitable donors are not unnecessarily deferred [2].

Blood donors are generally perceived to be healthy. However, some donors may be unfit or unsuitable for donating blood. Therefore, it is the responsibility of BTS to identify unsuitable donors and defer them as appropriate either temporarily or permanently. However, frequent and unnecessary donor deferral (especially temporary deferment) may lead to loss of potential blood donors some of whom may be reluctant to return for future donation [3, 4]. Knowledge of the rate and reasons for donor deferral is quite essential as this can guide future donor recruitment strategy. Therefore, the objectives of this study are to determine the proportion and reasons for donor deferral in University of Uyo Teaching Hospital (UUTH). This will help to ensure a more informed process of donor recruitment and selection and forestall unnecessary donor deferrals. It will also help our blood bank to develop strategies on how to follow-up temporarily deferred donors for future blood donation.

\section{MATERIALS AND METHODS}

Study Site: This study was conducted at the Blood Bank, University of Uyo Teaching Hospital a tertiary care center that provides specialized healthcare services to the residents of Uyo and neighboring states. The blood bank is hospital based, and it also provides blood banking services to peripheral healthcare facilities in Uyo and its environs.

Study Design: This study was a retrospective study of pre-donation deferral pattern of prospective blood donors at UUTH blood bank-a tertiary hospital in South-South Nigeria. The records of all prospective blood donors who presented at the UUTH blood bank from January 2009 to December 2012 were reviewed. The donors were either classified as fit for donation or as unfit or deferred donors. Records of all pre-donation deferrals over the stated period above were obtained. Blood donor selection criteria were in accordance with the World Health Organization (WHO) blood donor selection and counseling guidelines [2].

Data collection and Analysis: Data of all blood donors and pre-donation deferrals over the stated period were obtained using a pre-tested structured questionnaire designed for the study. The data were analyzed using SPSS window version 11.5 and Microsoft excel. Descriptive and inferential statistics were used as appropriate. Significant level was set at $5 \%(\mathrm{p}<0.05)$.

Ethical consideration: Ethical approval was obtained from the Ethic and Research Committee of the hospital before the commencement of this study.

\section{RESULTS}

The data of 5,636 prospective blood donors, who presented at the UUTH blood bank from January 2009 to December 2012, were studied of whom 4,733 (84\%) were males and 906 (16\%) were females. The female donors were significantly younger than male donors. The age range of female donors was $14.5-42.9$ years with a mean of 28.7 years while that of male donors was 30.9 years with a range of 16.1-45.7 years. Majority of the donors (49.1\%) were between the ages of 21-30 years (Table 1). Family replacement donors constitute $89.1 \%(5,021)$ of the entire donor population; the remainders, 10.9\% (615) were voluntary non-remunerated donors (Table 2).

Within the period under review, 902 donors representing $16 \%$ of the entire donor population were deferred from donation for various reasons. The total

Table 1: Age and sex distribution of blood donors in UUTH from January 2009 - December 2012.

\begin{tabular}{|c|c|c|c|c|}
\hline \multirow[t]{2}{*}{ Variables } & \multicolumn{2}{|c|}{ Sex } & \multirow{2}{*}{$\begin{array}{c}\text { Total } \\
\mathrm{n}=5,636(\%)\end{array}$} & \multirow[t]{2}{*}{ Statistical indices } \\
\hline & $\begin{array}{c}\text { Male } \\
\mathrm{n}=4,733(\%)\end{array}$ & $\begin{array}{c}\text { Female } \\
\mathrm{n}=903(\%)\end{array}$ & & \\
\hline \multicolumn{5}{|l|}{ Age group } \\
\hline 20 and below & $247(5.2)$ & $74 \quad(8.2)$ & $321 \quad(5.7)$ & $\mathrm{P}$ value $<0.0001^{+^{*}}$ \\
\hline $21-30$ & $2322(49.1)$ & $549(60.8)$ & $2871(50.9)$ & $\mathrm{Df}=5$ \\
\hline $31-40$ & $1642(34.7)$ & 217 (24.0) & $1859(33.0)$ & $\chi^{2}=75 \cdot 3839$ \\
\hline $41-50$ & $462(9.8)$ & $56 \quad(6.2)$ & $518 \quad(9.2)$ & \\
\hline $51-60$ & $58 \quad(1.2)$ & $5 \quad(0.6)$ & $63 \quad(1.1)$ & \\
\hline 61 and above & $2(0.04)$ & $2 \quad(0.2)$ & $4 \quad(0.1)$ & \\
\hline Mean (SD) & $30.9(7.4)$ & $28.7(7.1)$ & $30.5(7.4)$ & $\begin{array}{c}\mathrm{p} \text { value }<0.0001^{+} \\
\mathrm{df}-5634 \\
\mathrm{tt}=-8.1339\end{array}$ \\
\hline
\end{tabular}

+ Significant $\mathrm{p}$ value, ${ }^{*}$ fischer's exact test 
number of male donors and female donors who were deferred was 588 (12.4\%) and 314 (34.4\%), respectively (Table 3).

Analysis of the deferrals showed that positivity for any of the TTIs and hypertension were the reasons for permanent deferral $50.4 \%$ and $3.1 \%$, respectively while anemia (39\%), underage, i.e., $<18$ years $(6.8 \%)$ and underweight, i.e., $<45 \mathrm{~kg}(2.4 \%)$ were the reasons for temporary deferrals (Table 4).

There were twice as many female donors who had hemoglobin $<12.5 \mathrm{~g} / \mathrm{dL}$ as were male donors (Table 5 ).

The human immunodeficiency virus (HIV), hepatitis B surface antigen (HBsAg), and hepatitis C virus (HCV) positivity constituted a significant proportion of the TTIs (Table 6).

\section{DISCUSSION}

Table 2: Types of blood donors from (2009-2012).

\begin{tabular}{lcc} 
Types of donors & Frequency & Percentage \\
\hline Voluntary & 615 & 10.9 \\
Replacement & 1021 & 89.1 \\
\hline
\end{tabular}

Table 3: Sex distribution and frequency of deferrals of blood donors in UUTH.

\begin{tabular}{lcc}
\hline Sex & No of Donors & No of Deferrals (\%) \\
Male & 4,733 & $588(12.4)$ \\
Female & 903 & $314(34.8)$ \\
\hline
\end{tabular}

Table 4: Reason for deferral among blood donors in UUTH

\begin{tabular}{lcc} 
Reasons & Frequency & Percentage \\
\hline Hemoglobin $<12.5 \mathrm{~g} / \mathrm{dL}$ & 352 & 39.0 \\
Hypertension & 28 & 3.1 \\
Weight $<45 \mathrm{~kg}$ & 22 & 2.4 \\
Age $(<18$ years $)$ & 61 & 6.8 \\
TTIs & 455 & 50.4 \\
\hline
\end{tabular}

An appropriate process of blood donor selection is very important in achieving safety in blood transfusion, as the desired aim is to protect and safeguard the health of both the donor and the recipient of blood and blood products. However, unnecessary deferral of blood donors may results in the loss of potential donors particularly in our society, where the culture of blood donation is still very poor.

Majority of the blood donors in this study were family replacement donor and the remaining (10.9\%) were voluntary non-remunerated donors.

This pattern of donor population is similar to that reported in Kano, Northeast Nigeria in which family replacement donor constitutes over $95.7 \%$ of the donor population [5]. It is also similar to a study in Ain Shams University Hospital blood bank in Egypt in which family replacement donor constitute $87.7 \%$ of donors compared to $12.3 \%$ voluntary donors [6]. However, this contrast a study in a centralized blood transfusion service in Jos, Nigeria, where voluntary blood donors (78.2\%) constitute a larger proportion of the donor population than family replacement donors (22.4\%) [7]. This sharp contrast may be due to the fact that most blood transfusion services undertake regular mobile blood drives and donor sensitization and awareness campaign than hospital based blood banks. Also, like most other studies in Africa with similar population demographics and socioeconomic status, most of our donors were males with females accounting for $16 \%$ of the donors [8-10].

Various studies have reported different rates of donor deferrals. These differences differ from one region to another and also from one blood center to another even within the same region. While some studies reported rates as low as between $4-6 \%[11,12]$, others have reported rates as high as between $15-21 \%$ [13-16]. A donor deferral rate of $16 \%$ obtained in this study closely approximate those of the later studies. The differences in the deferral rates may probably be due to the differences in the donor selection criteria used in the different studies.

Anemia constitutes the most common cause of temporary deferrals among the blood donors in this study.

Table 5: Distribution of hemoglobin concentration of Blood Donors.

\begin{tabular}{lcccc}
\hline Hb $(\mathrm{g} / \mathrm{dL})$ & Level Male $\mathbf{n}=\mathbf{4 7 3 3}(\%)$ & Female $\mathbf{n}=\mathbf{9 0 3}(\%)$ & Total $\mathbf{n}=\mathbf{5 6 3 6}$ & Statistical indices \\
\hline 12.5 & $4612(87.3)$ & $672(74.4)$ & $5284(93.8)$ & $\mathrm{p}<0.0001$ \\
$\leq 12.5$ & $121(12.7)$ & $231(25.6)$ & $352(6.3)$ & $\mathrm{Df}=1, \mathrm{X} 2=686.569$ \\
\hline
\end{tabular}

Table 6: Percentage distribution of transfusion transmissible infection among deferred donors and the entire donor population.

\begin{tabular}{|c|c|c|c|}
\hline TTIs & Number & $\%$ total deferrals $n=902$ & $\%$ total donor population $n=5636$ \\
\hline HIV & 164 & 18.2 & 2.9 \\
\hline HBSAg & 150 & 16.6 & 2.7 \\
\hline $\mathrm{HCV}$ & 130 & 14.4 & 2.3 \\
\hline Syphilis & 43 & $4 \cdot 3$ & 0.8 \\
\hline
\end{tabular}


This finding is consistent with many other studies both in the developed and developing countries. In Canada, for instance $2 \%$ of the blood donors do not met the minimum acceptable hemoglobin level for eligible donors [17]. The figure is much higher in developing countries as recorded in this study and other studies from countries with similar demography and socio-economic characteristics $[18,19]$.

The deferral rate among the blood donors was significantly higher in female than male donors $(\mathrm{p}=<$ o.0001). This finding is in agreement with that of other studies [20, 21]. Also, more female donors were deferred on account of low hemoglobin than male donors. Similar observations have been reported in many other studies especially those from developing countries [12, 18, 19, 21]. The reasons for these are not far-fetched given the high rate of infection especially malaria and poor nutrition prevalent in most developing countries in SubSaharan Africa, coupled with the monthly menstrual blood loss. All these factors contribute to the high rate of anemia observed among these women. Thus, this calls for adequate nutritional advice including iron supplement for female donors. This is particularly very important for regular blood donors especially female donors since frequent blood donation has been reported to contribute significantly to iron deficiency anemia [22].

In addition to anemia, underage and underweight were also reasons for temporary deferrals of donors in this study. These findings are similar to that reported by Rehman et al. in their study [21]. WHO fact sheet on Blood Safety and Availability shows that $6 \%$ of blood donors globally come from underage group [23]. In a society like ours where blood donation is still viewed with much skepticism, the outright deferral of underage donors should be discouraged as this may negatively affects their future intension to donate blood. Rather, parental consent should be sought from underage donors. Parental consent from underage donors is a common practice in some blood centers in United State of America (USA) [24, 25].

This study has also shown that half of the donors were deferred on account of being positive to the TTIs. This figure is much higher than that reported in other studies. In a study by Rehman et al., 36.3\% of donors were deferred for permanent reasons of which the TTIs particularly HBV (23.5\%) infection was the major reason for the deferral [21]. In our study, HIV infection was the most common TTIs among the deferred donors followed by HBV, HCV and syphilis. This high figure may be attributed to the high proportion of family replacement donor in our study. Some studies have shown that family replacement donors are not true voluntary blood donors since they donate under family influence and in some cases, are hired commercial blood donors who pretend to be family members or relatives. Hence, they may not disclose relevant medical information such as previous history of jaundice or multiple unprotected sexual exposures [26]. The implication of this is that false medical information will be obtained from such donors and this may ultimately compromise the safety of the entire blood collection process. Also, the relatively high prevalence of these infections (TTIs) in our country may also be contributing factor.

The 2012 sentinel study puts the HIV seroprevalence rate in Nigeria at 3.4\% with Akwa Ibom state where this study was conducted having a rate of $6.5 \%$ [27]. The same applies to HCV and HBV infection with a country wide prevalence ranging from $0.5-12.3 \%$ for $\mathrm{HCV}$ and $1.2 \%$ and $26 \%$ among adult population including replacement donors for HBV infection [28-31]. Also, male donors had higher TTIs rate than the female donors. This observation may probably be due to the fewer numbers of female donors recorded in this study. In addition, this study has shown that hypertension accounts for $3.1 \%$ of donor deferrals. This rate is much lower than that (29.4\%) reported by Bahadur et al. [32]. Also Saunder et al., reported hypertension in 112 out of 156 potential donors who where permanently deferred [12]. Perhaps, having majority of our donors in the age group 40 years and below may have accounted for the low rate of hypertension as a cause for donor deferral in this study. The risk of developing this medical condition increases with age.

\section{CONCLUSION}

Blood donor deferral rates of $16 \%$ obtained in this study is similar to that reported in some other studies. However, the reasons for the deferrals differ reflecting some differences in donor selection criteria. Furthermore, positivity for transfusion transmissible infectious was the major reason for permanent deferral, while anemia was the major reason for temporary deferral of donors. Also, considering the relatively high proportion of female donors deferred on account of anemia we suggest nutritional advice and iron supplementation for all female donors.

$* * * * * * * * *$

\section{Author Contributions}

Timothy Amos Ekwere - Substantial contributions to conception and design, Acquisition of data, Analysis and interpretation of data, Drafting the article, Revising it critically for important intellectual content, Final approval of the version to be published

Mabel Ino-Ekanem - Analysis and interpretation of data, Drafting the article, Revising it critically for important intellectual content, Final approval of the version to be published

Olugbemi Oluseyi Motilewa - Analysis and interpretation of data, Drafting the article, Revising it critically for important intellectual content, Final approval of the version to be published

Iquo Augustine Ibanga - Analysis and interpretation of data, Drafting the article, Revising it critically for 
important intellectual content, Final approval of the version to be published

\section{Guarantor}

The corresponding author is the guarantor of submission.

\section{Conflict of Interest}

Authors declare no conflict of interest.

\section{Copyright}

(C) 2014 Timothy Amos Ekwere et al. This article is distributed under the terms of Creative Commons Attribution License which permits unrestricted use, distribution and reproduction in any medium provided the original author(s) and original publisher are properly credited. Please see the copyright policy on the journal website for more information.

\section{REFERENCES}

1. World Health Organization. Towards $100 \%$ voluntary blood donation. Available online: www.who.int/ entity/bloodsafety/publications/9789241599696_ eng.pdf

2. World Health Organization. Blood donor selection and counseling. Available online: www.who.int/ bloodsafety/voluntary_donation/blood_donor_ selection.../en/

3. Custer B, Chinn A, Hirschler NV, Busch MP, Murphy EL. The consequences of temporary deferral on future whole blood donation. Transfusion 2007;47(8):151423.

4. Zou S, Musavi F, Notari EP, Rios JA, Trouern-Trend J, Fang CT. Donor deferral and resulting loss at the American Red Cross Blood Services, 2001 through 2006. Transfusion 2008;48(12):2531-9.

5. Kuchiya-Gwarzo A, Kwaru AH. Pattern of blood donation in Aminu Kano Teaching Hospital. J Med Rehab 2007;1:35-8.

6. Abdel Messih IY, Ismail MA, Saad AA, Azer MR. The degree of safety of family replacement donor versus voluntary non remunerated donors in an Egyptian population. Acomparative study. Blood Transfus 2014;12(2):159-65.

7. Damulak OD, Bolorunduro SO, Boman F, Bako L. Pattern of blood donors in Jos. Jos journal of Medicine 2011;5(2).

8. Agbovi KK, Kolou M, Feteke L, Haudrechy D, North ML, Segbena AY. Knowledge Attitude and Practice about blood donation: A sociological study among the population in Lome in Togo. Transfus Clin Biol 2006;13(4):260-5. [Article in French].

9. Nébié KY, Olinger CM, Kafando E, et al. Lack of knowledge among blood donation in Burkina Faso (West Africa): Potential obstacle to transfusion security. Transfus Clin Biol 2007;14(5):446-52. [Article in French].

10. Allain JP, Sarkodie F, Boateng P, Asenso K, Kyeremateng E, Owusu-Ofori S. A pool of repeated bloods can be generated with little expense to the blood centre in Sub Sahara Africa. Transfusion
2008;48(4):735-41.

11. Talonu T. Causes of Volunteer blood donor rejection in Paupa New Guinea. P N G Med J 1983;26(34):195-7.

12. Saunder P, Sangeetha SK, Seema DM, Marimuthu P, Shivanna N. Pre-donation deferral of blood donors in South Indian Set-up: An Analysis. Asian J Transfus Sci 2010;4(2):112-5.

13. Shaz BH, James AB, Hillyer KL, Schreiber GB, Hillyer CD. Demographic variations in blood donor deferral in a major metropolitan area. Transfusion 2010;50(4):881-7.

14. Chaudhry RK, Gupta D, Gupta RK. Analysis of donor-deferral pattern in a voluntary blood donor population. Transfus Med 1995;5(3):209-12.

15. Kagu MB, Ahmed SG, Bashir MA, et al. Deferral patterns of voluntary blood donors at the National Blood Transfusion Service, North East Zonal Centre, Maiduguri. Afr J Med Med Sci 2010;39(2):119-25.

16. Di Lorenzo Oliveira C, Loureiro F, de Bastos MR, Proietta FA, Cameiro-Proietti AB. Blood donor deferral in Minas Gerais State, Brazil: blood centers as sentinels of urban population health. Transfusion 2009;49(5):851-7.

17. Ali AM, Goldsmith $\mathrm{CH}$, McAvory AT, Ali MA, Blajchman MA. A prospective study evaluating the lowing of haemoglobin standards for blood donors. Transfusion 1989;29(3):268-72.

18. Birjandi F, Gharehbaghian A, Delavari A, Rezaie N, Maghsudlu M. Blood donor deferral pattern in Iran. Arch Iran Med 2013;16(11):657-60.

19. Kouao MD, Dembelé B, N'Goran LK, et al. Reasons for blood donation deferral in Sub-Sahara Africa: Experience in Ivory Coast. Transfusion 2012;52(7 Pt 2):1602-6.

20. Arslan O. Whole blood donor deferral rate and characteristics of the Turkish population. Transfus Med 2007;17(5):379-83.

21. Rehman S, Arif SH, Mehdi G, Mirza S, Saeed N, Yusuf F. The evaluation of blood donor deferral causes: A tertiary care centre-based study. J Blood Disorders Transf 2012:131.

22. Adediran A, Uche EI, Adeyemo TA, Damulak DO, Akinbami AA, Akanmu AS. Iron stores in regularblood donors in Lagos, Nigeria. J Blood Med 2013;4:75-80.

23. World Health Organization. Blood Safety and Availability. Available online: www.who.int/ mediacentre/factsheet/.../en.

24. Blood Source. Parental consent form. Available online: www.bloodsource.org/linkclick.aspx?fileticket... tabid $=75$.

25. Utah Blood.org/ Donor Qualification. Available online: www.utahblood.org/donor-qualification/ donor-qualifications.htlm.

26. Jain R, Gupta G. Family/Friend donors are not true voluntary blood donors. Asian J Transfus Sci 2012;6(1):29-31.

27. National HIV/AIDS And Reproductive survey 2012. Available online: www.informationng.com/.../2012hivaids-and-reproductve-hea.

28. Alao O, Okwori E, Araoye M. Sero-prevalence of Hepatitis $\mathrm{C}$ virus (HCV) infection among prospective blood donors in Markudi, Nigeria. Internet J Infect Dis 2010;8(1). 
29. Chukwu EF, Ogbodo SO, Obi GO. Sero-prevalence of Hepatitis C virus among blood donors in SouthEastern State of Nigeria. Biomed Res 2005;16(2):1335 .

30. Umolu PI, Okoror LE, Orhue P. Human immunodeficiency virus (HIV) seropositivity and hepatitis B surface antigenemia (HBSAG) among blood donors in Benin city, Edo state, Nigeria. Afr Health Sci 2005;(1):55-8.

31. Muktar HM, Suleiman AM, Jones M. Safety of blood transfusion: Prevalence of Hepatitis B surface antigen in blood donors in Zaria, Northern Nigeria. Nig J Surg Res 2005;7(3):290-2.

32. Bahadur S, Jain S, Goel RK, Pahuja S, Jain M. Analysis of blood donor deferral characteristics in Delhi, India. Southeast Asian J Trop Med Public Health 2009;40(5):1087-91.

\section{ABOUT THE AUTHORS}

Article citation: Ekwere TA, Ino-Ekanem M, Motilewa OO, Iquo Augustine Ibanga. Pattern of blood donor deferral in a tertiary hospital, South-south, Nigeria: A three-year study review. Int J Blood Transfus Immunohematol 2014;4:7-13.

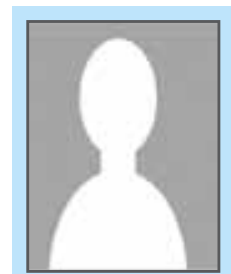

Timothy Amos Ekwere is Lecturer-1 and Consultant Hematologist at Department of Hematology University of Uyo/University of Uyo Teaching Hospital, Uyo, Nigeria. He earned the undergraduate degree MB,BCh from College of Medical Sciences, University of Calabar, Calabar, Nigeria and postgraduate degree from National Postgraduate Medical College of Nigeria (Fellow of Medical College of Nigeria in Pathology- FMCPath) from Department of Haematology and Blood Transfusion, Lagos University Teaching Hospital, Lagos, Nigeria. His research interests include hemostasis and thrombosis, plasma fractionation and immunohaematology. He intends to pursue PhD Programme in future.

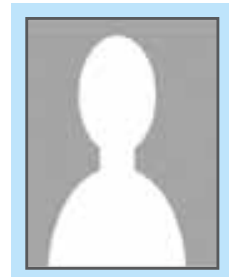

Mabel Ino-Ekanem is Lecturer-1 and Consultant Hematologist, Department of Hematology university of Uyo/University of Uyo Teaching Hospital, Uyo, Nigeria. She earned the undergraduate degree MB, BCh from College of Medical Sciences, University of Calabar, Nigeria and postgraduate degree from National Postgraduate Medical College of Nigeria (Fellow of Medical College of NigeriaPathology (FMCPath)) from Department of Hematology, University College Hospital, Ibadan, Nigeria. Her research interests include transfusion medicine, hemoglobinopathies.

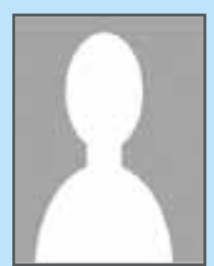

Oluseyi O. Motilewa is Lecturer-1 and Consultant Public Health Physician at Department of Community Health, University of Uyo/University of Uyo Teaching Hospital, Uyo, Nigeria. He earned the undergraduate degree MB,BS from Ahmadu Bello University, Zaria, Nigeria and postgraduate degree from National Postgraduate Medical College of Nigeria (Fellow of Medical College-Public Health (FMCPH)) from Department of Community Health, University of Uyo Teaching Hospital, Uyo, Nigeria. His research interests include disease control, quality of life. He intends to pursue a Postdoctoral Fellowship in future.

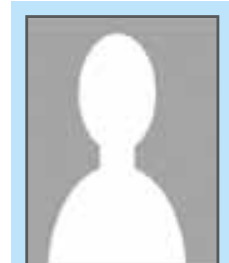

Iquo A. Ibanga is Senior Lecturer and Consultant Hematologist at Department of Hematology University of Calabar/University of Calabar Teaching Hospital, Calabar, Nigeria. She earned the undergraduate degree MB,BCh from College of Medical Sciences, University of Calabar, Calabar, Nigeria and postgraduate degree from National Postgraduate Medical College of Nigeria (Fellow of Medical College-Pathology (FMCPath)) from Department of Hematology Obafemi Awolowo University Teaching Hospital, Ile-Ife, Nigeri. Her research interests include transfusion medicine, hemoglobinopathies. 
Access full text article on other devices

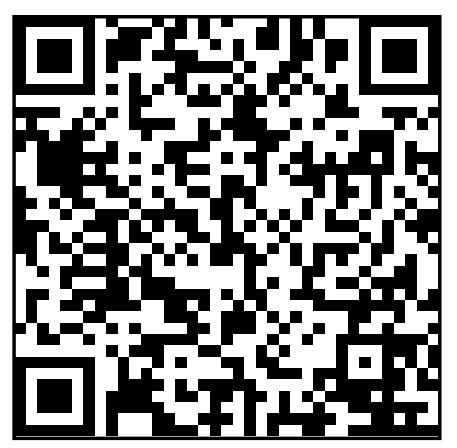

Access PDF of article on other devices

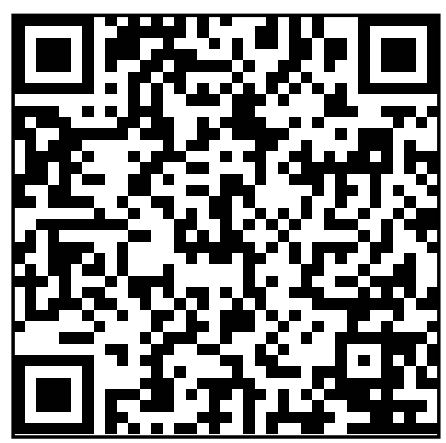

